\title{
Knowledge of pregnant women on mother-to-child transmission of HIV, its prevention, and associated factors in Assosa town, Northwest Ethiopia
}

This article was published in the following Dove Press journal:

HIVIAIDS - Research and Palliative Care

5 May 2016

Number of times this article has been viewed

\author{
Solomon Abtew \\ Worku Awoke \\ Anemaw Asrat \\ College of Medicine and Health \\ Sciences, Bahir Dar University, Bahir \\ Dar, Ethiopia
}

Introduction: HIV/AIDS is a leading cause of death of children in sub-Saharan African countries. Almost all HIV-positive children acquire infection through mother-to-child transmission (MTCT) of HIV. Successful intervention toward prevention of mother-to-child transmission (PMTCT) and achieving the goal of eliminating the new HIV infection is highly dependent on everyone; especially, women of child-bearing age should have accurate and up-to-date knowledge about HIV transmission, risk of transmission to babies, and possible interventions. However, knowledge of MTCT of HIV, its prevention, and associated factors among women was not well studied in Benshangul Gumuz Region (Ethiopia).

Methods: A facility-based cross-sectional study was conducted involving 398 pregnant women who attended antenatal care services at governmental health institutions from February to March 2014 in Assosa town. Based on the flow of antenatal care attendants, the calculated sample size was proportionally allocated to the health facilities before data collection. Following this, systematic sampling method was used, and data were collected using an interviewer-administered questionnaire. Bivariate and multivariate binary logistic regression analysis was done using SPSS version 20 statistical packages.

Result: A total of 386 pregnant women participated with a response rate of $97 \%$, and $222(57.5 \%)$ of them had full knowledge about the three critical modes of HIV transmission from mother to child, but only 67 (17.4\%) knew the possible prevention methods. Knowledge on MTCT of HIV was positively associated with women who had sufficient knowledge on HIV/AIDS (adjusted odd ratio $[\mathrm{AOR}]=2.86,95 \%$ confidence interval $[\mathrm{CI}]=1.54-5.32)$, women who had a favorable attitude to provider-initiated HIV counseling and testing ( $\mathrm{AOR}=2.19,95 \% \mathrm{CI}=1.22-3.92$ ), and women who did not expect any partner's reaction to positive HIV test result after testing (AOR $=1.58,95 \% \mathrm{CI}=1.01-2.49$ ). Correspondingly, knowledge on PMTCT of HIV was positively associated with women who had sufficient knowledge on HIV/AIDS (AOR $=2.64,95 \%$ $\mathrm{CI}=1.24-5.65)$, women who had favorable attitude toward provider's counseling and testing ( $\mathrm{AOR}=4.27,95 \% \mathrm{CI}=1.95-9.34$ ), and women who did not expect any partner's reaction to positive HIV test result after testing ( $\mathrm{AOR}=3.56,95 \% \mathrm{CI}=1.58-8.01)$.

Conclusion: Knowledge on MTCT and its prevention among women is low in the study area. We recommend more efforts to be exerted on improving women's knowledge of PMTCT of HIV.

Keywords: pregnant women, mother-to-child transmission and prevention, Assosa

\section{Introduction}

The HIV pandemic still remains an issue of major concern on a global scale. A total of 35.3 million people are living with HIV; of these, an estimated 2.3 million are newly infected. ${ }^{1}$ Sub-Saharan Africa contributes more than two-thirds (69\%) of the global 
infected population. Children under the age of 15 account for 3.4 million of the global number of infected, while subSaharan Africa alone contributes to $90 \%$ of this burden. ${ }^{2}$

The most significant source of HIV infection in children and infants is transmission of HIV from mother to child during pregnancy, childbirth, or breastfeeding. Without intervention, the risk of transmission varies ranging from 5\% to $10 \%$ during pregnancy, $10 \%$ to $15 \%$ during labor/delivery, and $5 \%$ to $20 \%$ through breastfeeding. 3,4

Ethiopia is also one of the largest epidemic countries in sub-Saharan Africa. The national HIV prevalence estimate was $1.5 \%$, but the prevalence in women was $1.9 \%$ in $2011 .^{5}$ Increased incidence of HIV in pregnant women would ultimately lead to increased incidence of HIV in children. Among the total 137,494 new HIV infections, 10\% were children infected mainly due to vertical mother-to-child transmission of HIV (MTCT). ${ }^{6,7}$

The proportion of HIV-positive mothers identified at sites of prevention of mother-to-child transmission (PMTCT) of HIV was only $22.1 \%$ in 2010, and at the national PMTCT services scale-up site was $61.9 \%{ }^{8}$ From this PMTCT service site, only $75.5 \%$ of antenatal care (ANC) attendants were tested for HIV. ${ }^{6}$ According to the Ethiopian Demographic and Health Survey of 2011 , only $34 \%$ and $9.9 \%$ of mothers received antenatal care from health professionals, and delivered at health institutions, respectively. ${ }^{5}$ To cope with the challenges, the Federal Ministry of Health planned to rapidly increase antiretroviral (ARV) service utilization to $77 \%$ of eligible pregnant women by 2015 as an intervention to PMTCT. ${ }^{7,8}$ But only $9.3 \%$ of pregnant women received ARVs in 2011. This also limits access to mothers and their babies who might require PMTCT intervention. ${ }^{6,7}$

Nowadays, for the phase of elimination of MTCT of HIV, a combination of ARVs, elective cesarean section, and abstinence from breastfeeding is recommended, through which it is possible to reduce MTCT of HIV to $<2 \%$ in developed countries. This is still not possible in resourcelimited countries. Primary prevention is considered the most important way to decrease MTCT of HIV. ${ }^{9}$ So, strengthening the integration of PMTCT services with maternal, sexual, reproductive health, and family planning services in health facilities is the most critical priority outlined for achieving the PMTCT targets. ${ }^{7}$ One of the pillars of PMTCT and the most cost-effective way is increasing the knowledge of pregnant mothers.

Several authors have argued that regardless of widespread information, education, and communication campaigns, and the extension of PMTCT services, women's knowledge on risk factors of MTCT of HIV and periods of transmission is greatly limited. This has significantly contributed to the ineffectiveness of the PMTCT strategy. ${ }^{10,11}$ PMTCT over the years has been an area of interest to many with a good number of studies carried out to access knowledge level of people. But women's knowledge of MTCT of HIV in Ethiopia is particularly low when compared to other East African countries. More than $65 \%$ of women in Kenya, Rwanda, Tanzania, and Uganda know about MTCT of HIV compared to $42 \%$ in Ethiopia. ${ }^{12}$

Knowledge on MTCT and PMTCT of HIV and factors that facilitate or hinder it is an important aspect of study among pregnant women, to facilitate PMTCT. In addition, it has not been studied in the context of Assosa town health facilities. The findings of the study will assist health professionals, programmers, and partners in refocusing their approach in the management of women during ANC follow-up for taking appropriate interventions so as to increase knowledge of pregnant women to promote primary prevention and early treatment to tackle HIV from MTCT.

\section{Methods}

A facility-based cross-sectional study was conducted from February to March 2014 in Assosa town. Assosa town is the capital city of Benshangul Gumuz, Regional State, located Northwest of Ethiopia at $680 \mathrm{kms}$ from Addis Ababa. According to the 2007 Central Statistics Agency report, the total population of the town was 24,214 (11,751 were females, and 12,463 were males). Amhara, Berta, and Oromo are predominant ethnic groups living in the town. Orthodox Tewahido, Muslim, and Protestant are the common religions. Amharic is the official language; moreover, other languages like Rurtangna and Oromifa are spoken widely. ${ }^{13}$ Administratively, the town is structured into four urban Kebeles. It has one health center, one general hospital, and seven private clinics. None of the clinics perform PMTCT services, but both governmental health facilities (hospital and health center) currently provide ANC and PMTCT services for pregnant mothers. ${ }^{14}$

The source population was all pregnant women who attended ANC services in Assosa town public health facilities. Pregnant women of child-bearing age, who were selected by sampling procedures during the study period in Assosa town public health facilities, were studied. The sample size was calculated using single-population proportion formula considering the following assumptions; 95\% confidence interval (CI), 56\% pregnant women had comprehensive knowledge on HIV/AIDS taken from another study, ${ }^{15}$ margin of error 
0.05 , and with the addition of $5 \%$ nonresponse rate. With this assumption, the total calculated sample size became 398. First, the sample size was proportionally allocated to the two health facilities based on the flow of ANC clients. Second, after the completion of the service, individual study participants were selected by systematic random sampling method by reviewing the chart. Finally, during selection, the first pregnant woman was selected randomly by lottery technique, and then every other ANC follower was included in the study.

\section{Operational definitions MTCT knowledge}

Knowledge index was built from the answers to three questions (MTCT during pregnancy, during delivery, and through breastfeeding); then, the index was categorized as full knowledge if the participants answered all these three questions, and not full knowledge if they answered less than three questions.

\section{PMTCT knowledge}

Knowledge index was built from the answers to three questions (using antiretroviral therapy [ART] drugs, safe delivery, and only breastfeeding up to 6 months); then, the index was categorized as not full knowledge (score $<3$ ) and full knowledge $($ score $=3$ ).

\section{Knowledge of HIVIAIDS}

Knowledge index was built from the answers to 13 questions: four questions on knowledge of HIV prevention, four questions on knowledge of HIV transmission, and five on misconceptions about modes of HIV transmission. Based on the responses to these knowledge questions, the index was categorized as insufficient knowledge (score $\leq 6$ ) and sufficient knowledge (score 7-13).

\section{Data collection and quality control}

The questionnaire was prepared in simple words by reviewing pertinent literature. ${ }^{15-17}$ It was pretested in the same setup prior to the actual data collection. Training was given to data collectors and supervisors. During data collection, completeness of the questionnaire was checked by supervisors daily. Data coding, cleaning, and verification were performed to assure the quality of data.

\section{Ethical consideration}

Ethical clearance and approval was obtained from Bahir Dar University, College of Medicine and Health Sciences. Written consents were obtained from Benshangul Gumuz Regional Health Bureau, Assosa Town Health Administration, and health facilities before data collection. Written consent was also obtained from each participant, and confidentiality was assured before conducting the data collection. Participants were given the right to withdraw from the study at any time without any requirements.

\section{Data management and analysis}

All collected raw data were entered into a computer by Epi Info 3.5.3 version software. Then, the data were exported to SPSS version 20 statistical package software for analysis. Descriptive statistics such as proportion and frequencies were used to describe the study population in relation to relevant variables. Bivariate analysis was done for all explanatory variables in relation to knowledge on MTCT and PMTCT of HIV, and those variables with $P<0.2$ were entered into multivariate logistic regression analysis using the backward stepwise method. The model was checked by using Hosmer and Lemeshow test of fitness.

\section{Results}

From the total 398 pregnant women expected to be included in this study, 386 participated fully yielding a response rate of $97 \%$. Of these participants, around three-quarters were urban residents. More than half of the study participants $(57.3 \%)$ were within the age range of 20-29 years. Three hundred and thirty-two (86\%) were Muslim and Orthodox Christians. Regarding ethnicity, number of participants from Amhara, Oromo, and Berta ethnic groups was 175 (45.3\%), $65(16.8 \%)$, and $89(23.1 \%)$, respectively. More than threequarters of the respondents attended formal education from elementary to higher level, whereas the rest were not attending any formal education. One hundred and forty-five (37.6\%) ANC followers were housewives, 123 (31.9\%) were employed by either government or private institutions, and $58(15 \%)$ were farmers. Almost half of pregnant mothers (50.8\%) had an income of $\geq 1,000$ Ethiopian Birr for their household expenditure per month (Table 1).

\section{Knowledge of MTCT and its prevention}

More than half of the respondents (57.5\%) had full knowledge about MTCT of HIV, but only 67 (17.4\%) had knowledge on PMTCT of HIV/AIDS. Regarding transmission mode, $33.5 \%, 33.6 \%$, and $32.8 \%$ of mothers said that transmission of HIV from mother to child occurred during pregnancy, during delivery, and through breastfeeding, respectively. On the other hand, $36.9 \%, 34.9 \%$, and $28.2 \%$ of respondents 
Table I Sociodemographic characteristics of pregnant women attending antenatal care services in governmental health facilities of Assosa town, Northwest Ethiopia, 2014 ( $\mathrm{N}=386)$

\begin{tabular}{|c|c|c|}
\hline Variables & Number & Percent \\
\hline \multicolumn{3}{|l|}{ Age (years) } \\
\hline$\leq 19$ & 104 & 26.9 \\
\hline $20-29$ & 221 & 57.3 \\
\hline $30-45$ & 61 & 15.8 \\
\hline \multicolumn{3}{|l|}{ Residence } \\
\hline Rural & 88 & 22.8 \\
\hline Urban & 298 & 77.2 \\
\hline \multicolumn{3}{|l|}{ Ethnicity } \\
\hline Amhara & 175 & 45.3 \\
\hline Berta & 89 & 23.1 \\
\hline Oromo & 65 & 16.8 \\
\hline Shinasha & 24 & 6.2 \\
\hline Others & 33 & 8.6 \\
\hline \multicolumn{3}{|l|}{ Religion } \\
\hline Orthodox Christian & 165 & 42.7 \\
\hline Muslim & 167 & 43.3 \\
\hline Protestant & 49 & 12.7 \\
\hline Catholic & 5 & 1.3 \\
\hline \multicolumn{3}{|l|}{ Educational status } \\
\hline Cannot read and write & 47 & 12.2 \\
\hline Read and write & 40 & 10.4 \\
\hline Grade I-8 & 88 & 22.8 \\
\hline Grade 9-12 & 94 & 24.4 \\
\hline Grade $>12$ & 117 & 30.3 \\
\hline \multicolumn{3}{|l|}{ Occupation } \\
\hline Merchant & 32 & 8.3 \\
\hline Farmer & 58 & 15.0 \\
\hline Employed & 123 & 31.9 \\
\hline Student & 28 & 7.3 \\
\hline Housewife & 145 & 37.6 \\
\hline \multicolumn{3}{|l|}{ Marital status } \\
\hline Unmarried & 12 & 3.1 \\
\hline Married/living together & 364 & 96.1 \\
\hline Divorced & 3 & 0.8 \\
\hline \multicolumn{3}{|c|}{ Household expenditure (Ethiopian Birr/month) } \\
\hline No response & 96 & 24.9 \\
\hline$\geq 1,000$ & 196 & 50.8 \\
\hline$<1,000$ & 94 & 24.4 \\
\hline
\end{tabular}

knew that effective utilization of ART drugs, only breastfeeding up to 6 months, and having safe delivery can prevent MTCT of HIV (Table 2).

\section{Factors affecting knowledge on MTCT}

Compared to women who did not have sufficient knowledge on HIV/AIDS, those who had sufficient knowledge on HIV/ AIDS were 2.9 times (adjusted odd ratio [AOR] $=2.86$, 95\% CI $=1.54-5.32$ ) more likely to have better knowledge on MTCT of HIV. Women who had a favorable attitude to provider-initiated HIV testing and counseling (PITC) were 2.2 times $(\mathrm{AOR}=2.19,95 \% \mathrm{CI}=1.22-3.92$ ) more likely to have better knowledge on MTCT of HIV than those who had
Table 2 Knowledge on MTCT and PMTCT among pregnant women attending antenatal care services in governmental health facilities of Assosa town, Northwest Ethiopia, 2014 ( $\mathrm{N}=386)$

\begin{tabular}{llc}
\hline Variables & Number & Percent \\
\hline Full knowledge on MTCT & 222 & 57.5 \\
Yes & 164 & 42.5 \\
No & & \\
MTCT could occur* & 290 & 33.5 \\
$\quad$ During pregnancy & 291 & 33.6 \\
During delivery & 284 & 32.8 \\
During breastfeeding & 67 & 17.4 \\
Full knowledge on the existence of intervention to minimize & MTCT \\
Yes & 319 & 82.6 \\
No & & \\
PMTCT could be by* & 187 & 36.9 \\
ART drugs & 177 & 34.9 \\
Only breastfeeding up to 6 months & 143 & 28.2 \\
Safe delivery &
\end{tabular}

Note: *Analysis was done using multiple responses.

Abbreviations: ART, anti-retroviral treatment; MTCT, mother-to-child transmission; PMTCT, prevention of mother-to-child transmission.

a less favorable attitude. Pregnant women who did not expect any partner's reaction to positive HIV test result after testing were 1.6 times more likely $(\mathrm{AOR}=1.58,95 \% \mathrm{CI}=1.01-2.49)$ to have knowledge on MTCT of HIV than those who expected negative reaction from their partner. Age, ethnicity, religion, residence, educational status, monthly household expenditure, occupation, and marital status of respondents were significantly associated with knowledge on MTCT of HIV among ANC followers in the bivariate analysis, but all these variables did not retain their significance for multivariate analysis (Table 3).

\section{Factors affecting knowledge on PMTCT}

There was a statistically significant difference of knowledge on PMTCT of HIV among women with respect to their monthly household expenditure; participants who had $>1,000$ Ethiopian Birr for monthly expenditure were 3.5 times $(\mathrm{AOR}=3.46,95 \% \mathrm{CI}=1.26-9.51)$ more likely to have better knowledge of PMTCT of HIV as compared to those who had $\leq 1,000$ Ethiopian Birr. Respondents who had full knowledge on MTCT of HIV were 3.3 times $(\mathrm{AOR}=3.32$, $95 \% \mathrm{CI}=1.60-6.92$ ) more likely to have knowledge on PMTCT of HIV than those who did not have. Those respondents who had a favorable attitude to PITC were 4.3 times (AOR $=4.27,95 \% \mathrm{CI}=1.95-9.34)$ better knowledgeable than those who had a less favorable attitude to PITC, and respondents who did not expect any partner's reaction to positive HIV test result after testing were 3.6 times $(\mathrm{AOR}=3.56,95 \%$ $\mathrm{CI}=1.58-8.01$ ) more likely to have knowledge on MTCT of HIV than those who expected a negative reaction from their 
Table 3 Association between knowledge of MTCT and explanatory variables among pregnant women attending antenatal care services in governmental health facilities of Assosa town, Northwest Ethiopia, 2014 (N=386)

\begin{tabular}{|c|c|c|c|c|c|}
\hline \multirow[t]{2}{*}{ Variables } & \multicolumn{2}{|c|}{ Full knowledge on MTCT } & \multirow[t]{2}{*}{ COR $(95 \% \mathrm{Cl})$} & \multirow[t]{2}{*}{ AOR $(95 \% \mathrm{Cl})$} & \multirow[t]{2}{*}{$P$-value } \\
\hline & Yes & No & & & \\
\hline \multicolumn{6}{|l|}{ Residence } \\
\hline Urban & 185 & 113 & $2.57(1.39-3.66)$ & $1.61(0.95-2.73)$ & 0.077 \\
\hline Rural & 37 & 51 & 1.00 & 1.00 & \\
\hline \multicolumn{6}{|c|}{ Expected partner's reaction to positive HIV test result } \\
\hline Positive & 158 & 90 & $2.03(1.33-3.10)$ & $1.58(1.01-2.49)$ & 0.047 \\
\hline Negative & 64 & 74 & 1.00 & 1.00 & \\
\hline \multicolumn{6}{|c|}{ Sufficient knowledge on HIV/AIDS } \\
\hline Yes & 203 & 122 & $3.68(2.05-6.6 \mathrm{I})$ & $2.86(1.54-5.32)$ & 0.001 \\
\hline No & 19 & 42 & 1.00 & 1.00 & \\
\hline
\end{tabular}

Notes: The assumptions for the application of multivariate logistic regression analysis were fulfilled by using Hosmer and Lemeshow test, and the model was adequately fitted $(P=0.15 \mathrm{I})$. For explanatory variables having more than two categories, the overall significance of $P$-value was used. Significant values are in bold.

Abbreviations: MTCT, mother-to-child transmission; COR, crude odds ratio; Cl, confidence interval; AOR, adjusted odds ratio.

partner. Age, ethnicity, occupation, number of ANC visits, knowledge on HIV/AIDS, and stigmatized attitude toward people living with HIV/AIDS were significantly associated with knowledge on PMTCT of HIV among ANC followers in the bivariate analysis, but all of these variables did not retain their significance in multivariate analysis (Table 4).

\section{Discussion}

Improving knowledge on MTCT and PMTCT of HIV among populations at higher risk of HIV infection is essential in implementing comprehensive HIV responses like ARV prophylaxis for children who will be born from HIV-exposed mothers, initiating ART drugs for mothers based on option $\mathrm{B}+$ rules, and preventing extended pregnancies. In this study, $57.5 \%$ of ANC followers had full knowledge about MTCT of HIV. This proportion was much lower than from Ghana, Nigeria, and Gondar $(87.7 \%, 74.5 \%$, and $88.5 \%$, respectively). ${ }^{18-20}$ However, this proportion was a little bit higher than from Tanzania (50\%) and South Africa (38.3\%). ${ }^{21-22}$ The poor result in this study may be due to lack of proper counseling by health professionals during their ANC visit, or poor health education in the health facilities, especially regarding the three critical modes of HIV transmission from mother to child.

Lack of knowledge on MTCT of HIV among ANC followers contributed to the transmission of HIV from mother to children. In this study, a small proportion (17.5\%) of mothers knew that PMTCT of HIV could be prevented by use of ARV drugs, by only breastfeeding up to 6 months, and safe delivery. This proportion was less than that from Addis

Table 4 Association between knowledge of PMTCT and explanatory variables among pregnant women attending antenatal care services in governmental health facilities of Assosa town, Northwest Ethiopia, $2014(\mathrm{~N}=386)$

\begin{tabular}{|c|c|c|c|c|c|}
\hline \multirow[t]{2}{*}{ Variables } & \multicolumn{2}{|c|}{ Full knowledge on PMTCT } & \multirow[t]{2}{*}{ COR $(95 \% \mathrm{Cl})$} & \multirow[t]{2}{*}{ AOR $(95 \% \mathrm{Cl})$} & \multirow[t]{2}{*}{$P$-value } \\
\hline & Yes & No & & & \\
\hline \multicolumn{6}{|c|}{ Household monthly expenditure (Ethiopian Birr/month) } \\
\hline No response & 21 & 75 & $4.98(1.79-13.86)$ & 7.58 (2.49-23.09) & 0.002 \\
\hline$\geq 1,000$ & $4 I$ & 155 & $4.7 \mid(1.80-12.35)$ & $3.46(1.26-9.5 I)$ & \\
\hline$<1,000$ & 5 & 89 & 1.00 & 1.00 & \\
\hline \multicolumn{6}{|c|}{ Sufficient knowledge on HIVIAIDS } \\
\hline Yes & 65 & 260 & $7.38(1.76-30.97)$ & $3.65(0.78-16.99)$ & 0.099 \\
\hline No & 2 & 59 & 1.00 & 1.00 & \\
\hline \multicolumn{6}{|c|}{ Full knowledge on MTCT } \\
\hline Yes & 56 & 166 & $4.69(2.37-9.29)$ & $3.32(1.60-6.92)$ & 0.001 \\
\hline No & 11 & 153 & 1.00 & 1.00 & \\
\hline \multicolumn{6}{|c|}{ Expected partner's reaction to positive HIV test result } \\
\hline Positive & 58 & 190 & $4.38(2.09-9.14)$ & $3.56(1.58-8.01)$ & 0.002 \\
\hline Negative & 9 & 129 & 1.00 & 1.00 & \\
\hline
\end{tabular}

Notes: The assumptions for the application of multivariate logistic regression analysis were fulfilled by using Hosmer and Lemeshow test, and the model was adequately fitted $(P=0.7$ I5). For explanatory variables having more than two categories, the overall significance of $P$-value was used. Significant values are in bold.

Abbreviations: PMTCT, prevention of mother-to-child transmission; COR, crude odds ratio; $\mathrm{Cl}$, confidence interval; AOR, adjusted odds ratio; MTCT, mother-to-child transmission. 
Ababa and Gondar where $76.8 \%$ and $83.5 \%$ knew that MTCT of HIV is preventable..$^{20,23}$ In this study, $36.9 \%$ of pregnant women knew that ARV drugs have a preventive effect on MTCT of HIV, which is much lower than from Gondar study where $58.4 \%$ knew that MTCT of HIV could be prevented by ARV drugs. ${ }^{20}$ The poor result in this study could be due to the fact that pregnant women generally knew that MTCT of HIV is preventable, but they did not know the specific methods of prevention. This may result from the ineffectiveness of counseling, health education, and promotion services given by health facilities. This poor result may affect the goal of elimination of MTCT of HIV because the strategy is not only overplayed on the government and the health facilities but every pregnant woman should also know the critical method of prevention of MTCT to take appropriate interventions given by health facilities.

Among the sociodemographic factors, higher monthly expenditure had a positive association with full knowledge on PMTCT of HIV among pregnant women. The positive effect in this study could be due to the fact that those who had higher monthly expenditure might get information about PMTCT of HIV from different sources of information (newspapers and mass media). Due to this, they may develop confidence, and this confidence might lead them to independently get access to ANC, PMTCT, and PITC services. Also, they might get the chance to learn from health professionals. This information may enhance women's knowledge about PMTCT of HIV.

A positive association was reported between knowledge on MTCT and PMTCT of HIV and overall knowledge on HIV/AIDS among ANC followers in the study area. This finding was consistent with a study conducted in Northwest Ethiopia. ${ }^{20}$ The knowledge on MTCT and PMTCT of HIV also had a positive association with attitude of pregnant women to PITC and expected partner's reaction to positive HIV test result during their ANC follow-up. This could be due to the reason that those pregnant women who had sufficient knowledge about HIV/AIDS had a positive attitude to PITC during their ANC visit, and women who had smooth communication with their partner or expected positive reaction from their partner about HIV positive test result may have access to get knowledge on MTCT and PMTCT of HIV from health facilities during HIV testing and counseling, PMTCT services, communication with partner, and from other sources like mass media and newspaper. These possible explanations were consistent with a study conducted in Uganda, where women who had positive attitude may have more access to information about HIV from different sources. ${ }^{24}$ A study conducted in Meket District, Northeast
Ethiopia, also supports these possible explanations. Mothers who received information on HIV from health care provider and who had discussion with partner about MTCT were positively associated with increased maternal knowledge of MTCT of HIV. ${ }^{25}$

\section{Conclusion}

Knowledge of ANC attendants about MTCT and PMTCT in the study area was low. This may contribute to increased transmission of MTCT of HIV and lead to unsuccessful PMTCT intervention and hinder the achievement of the goal of eliminating new HIV infection in children by 2015 laid out in the United Nations Programme on HIV/AIDS global plan. Hence, key actors and implementors of PMTCT program should address or provide women with accurate and up-todate knowledge of HIV transmission, risk of transmission to babies, and interventions available to reduce and possibly eliminate the transmission of the virus to children.

\section{Acknowledgments}

The authors would like to thank Bahir Dar University, College of Medicine and Health Sciences, School of Public Health, and Assosa town public facilities. They are also grateful to the data collectors and study participants for their cooperation.

\section{Authors' contributions}

SA contributed to proposal development, data cleaning, data analysis, and manuscript preparation. WA and AA contributed to approval of the proposal development, data analysis, and manuscript preparation. All authors contributed toward data analysis, drafting and critically revising the paper and agree to be accountable for all aspects of the work.

\section{Disclosure}

The authors declare that they have no conflicts of interest in this work.

\section{References}

1. United Nations Programme on HIV/AIDS. Global report: UNAIDS report on the global AIDS epidemic 2013. Geneva: United Nations Programme on HIV/AIDS; 2013.

2. USAIDS. Sub-Saharan Africa regional fact sheet 2012. Available from: www.unaids.org/en/media/unaids/contentassets/documents/ epidemiology/2012/gr2012/2012FSregionalssaen.pdf. Accessed December 27, 2013.

3. World Health Organization. Mother to Child Transmission of HIV. Geneva: World Health Organization; 2011.

4. Volmink JA. HIV: Mother-to-Child Transmission. London: BMJ Publishing Group; 2008.

5. Central Statistical Agency [Ethiopia], ICF International. Ethiopia Demographic and Health Survey 2011. Addis Ababa: Central Statistical Agency; 2012. 
6. Federal Ministry of Health: health and health-related indicators report for EFY2003. Addis Ababa: Federal Ministry of Health; 2009.

7. Federal Ministry of Health: accelerated plan for scaling up prevention of mother to child transmission (PMTCT) services in Ethiopia. Addis Ababa: Federal Ministry of Health; 2011.

8. Nigatu T, WoldegebrielY. Analysis of the prevention of mother-to-child transmission (PMTCT) service utilization in Ethiopia: 2006-2010. Reprod Health. 2011;8:6.

9. Lynne M, Munderi M, Mofenson P. Saftey on anti retroviral prophylaxis of perinatal transmission of HIV infected pregnant women and their children. J AIDS. 2002;30(2):200-215.

10. Abiodun OM, Ijaiya AM, Aboyeji AP. Awareness and knowledge of mother to child transmission of HIV among pregnant women. $J$ Natl Med Assoc. 2007;99(7):758-763.

11. Orne-Gliemann J, Mukotekwa T, Perez F, et al. Improved knowledge and practices among end-users of mother-to-child transmission of HIV prevention services in rural Zimbabwe. Trop Med Int Health. 2006;11(3):341-349.

12. ICF International. HIV/AIDS in Ethiopia: data from the 2011 Ethiopian demographic health survey. Addis Ababa: ICF International; 2012.

13. Central Statistics Authority 2007 population and housing census in Ethiopia: administrative report. Addis Ababa: Central Statistics Authority; 2012

14. MOH. Guidelines for HIV counselling and testing in Ethiopia. Addis Ababa: Federal HIV/AIDS Prevention and Control Office; 2007.

15. Malaju MT, Alene GD. Assessment of utilization of provider-initiated HIV testing and counselling as an intervention for prevention of mother to child transmission of HIV and associated factors among pregnant women in Gondar town, North West Ethiopia. BMC Public Health. 2012;12:226

16. Haddis M, Jerene D. Awareness of antenatal care clients on motherto-child-transmission (MTCT) of HIV infection and its prevention in Arba Minch. Ethiopian J Health Dev. 2006;20(1)

17. Hasen T. Acceptability of provider initiated HIV counselling and testing in pregnant mothers attending ANC at Nekemte Town government health facilities. Sci Technol Arts Res J. 2012;1(3):24-30.
18. Boateng D, Kwapong GD, Agyei-Baffour P. Knowledge, perception about antiretroviral therapy (ART) and prevention of mother-tochild transmission (PMTCT) and adherence to ART among HIV positive women in the AshantiRegion, Ghana: a cross-sectional study. BMC Women's Health. 2013;13(2).

19. Lamina MA. A survey of awareness and knowledge of mother-to-child transmission of HIV in pregnant women attending OlabisiOnabanjo University Teaching Hospital, Sagamu, Nigeria. Open J Obstet Gynecol. 2012;2:98-105.

20. Malaju MT, Alene GD. Determinant factors of pregnant mothers' knowledge on mother to child transmission of HIV and its prevention in Gondar town, North West Ethiopia. BMC Pregnancy Childbirth. 2012;12:73

21. Wangwe PJ, Nyasinde M, Charles DS. Counselling at primary health facilities and level of knowledge of antenatal attendees and their attitude on prevention of mother to child transmission of HIV in Dar-es salaam, Tanzania. Afr Health Sci. 2013;13(4):914-919.

22. Useh U, Keikepe A, Montshiwagae B, Mothoagae R, Senna D. Knowledge and attitude of pregnant women towards mother to child transmission (MTCT) of HIV and AIDS in a local clinic in Mafikeng, South Africa. Ethno Med. 2013;7(3):163-169.

23. Solomon J, Tilahun T. Knowledge and attitude towards mother to child transmission of HIV and its prevention among postnatal mothers in Tikur Anbessa and Zewditu Memorial Hospitals Addis Ababa. Ethiop J Health Dev. 2005;19(3):211-218.

24. Byamugisha R, Tumwine JK, Ndeezi G, Karamagi CAS, Tylleskär T. Attitudes to routine HIV counselling and testing, and knowledge about prevention of mother to child transmission of HIV in eastern Uganda: across-sectional survey among antenatal attendees. J Int AIDS Soc. 2010;13:52.

25. Tesfaye Birhane T, Assefa GT, Addis KA, Fekadu AD. Knowledge of pregnant women on mother-to-child transmission of HIV in Meket District, Northeast Ethiopia. J Pregnancy. 2015. Article ID 960830.
HIV/AIDS - Research and Palliative Care

\section{Publish your work in this journal}

HIV/AIDS - Research and Palliative Care is an international, peerreviewed open-access journal focusing on advances in research in HIV, its clinical progression and management options including antiviral treatment, palliative care and public healthcare policies to control viral spread. The journal welcomes original research, basic science,

\section{Dovepress}

clinical \& epidemiological studies, reviews \& evaluations, expert opinion \& commentary, case reports \& extended reports. The manuscript management system is completely online and includes a very quick and fair peer-review system. Visit http://www.dovepress.com/ testimonials.php to read real quotes from published authors. 